\title{
Erosional response of an actively uplifting mountain belt to cyclic rainfall variations
}

\author{
J. Braun, C. Voisin, A. T. Gourlan, and C. Chauvel \\ ISTerre, Université Grenoble Alpes and CNRS BP 53, 38041 Grenoble CEDEX 9, France \\ Correspondence to: J. Braun (jean.braun@ujf-grenoble.fr)
}

Received: 25 July 2014 - Published in Earth Surf. Dynam. Discuss.: 26 August 2014

Revised: 18 November 2014 - Accepted: 8 December 2014 - Published: 5 January 2015

\begin{abstract}
We present an approximate analytical solution to the stream power equation describing the erosion of bedrock in an actively uplifting mountain range subject to periodic variations in precipitation rate. It predicts a time lag between the climate forcing and the erosional response of the system that increases with the forcing period. The predicted variations in the sedimentary flux coming out of the mountain are also scaled with respect to the imposed rainfall variations in a direct proportion to the discharge exponent, $m$, in the stream power law expression. These findings are confirmed by 1-D and 2-D numerical solutions. We also show that the response of a river channel is independent of its length and thus the size of its catchment area, implying that all actively eroding streams in a mountain belt will constructively contribute to the integrated signal in the sedimentary record. We show that rainfall variability at Milankovitch periods should affect the erosional response of fast uplifting mountain belts such as the Himalayas, Taiwan or the South Island, New Zealand, and predict 1000 to 10000 -year offsets between forcing and response. We suggest that this theoretical prediction could be used to independently constrain the value of the poorly defined stream power law exponents, and provide an example of how this could be done, using geochemical proxy signals from an ODP borehole in the Bengal Fan.
\end{abstract}

\section{Introduction}

Much work has been devoted to studying the potential links that might exist between climate and surface processes, and in particular the erosion of high-relief, tectonically active mountain belts (Tucker and Slingerland, 1997; Whipple et al., 1999; Zhang et al., 2001; Boggart et al., 2003; Whipple and Meade, 2006; Willett et al., 2006; Strecker et al., 2007; Whipple, 2009; Wobus et al., 2010; DiBiase and Whipple, 2011; Champagnac et al., 2012; Herman et al., 2014). This is in turn important to understand whether climate can affect tectonics as suggested by several now highly quoted studies (Molnar and England, 1990; Willett et al., 1993; Montgomery, 1994; Montgomery et al., 2001). Because glacial erosion is more efficient than fluvial processes, it is now reasonably well established that Cenozoic climate cooling culminating in the onset of periodic glaciations in the Quaternary has led to enhanced erosion rates in many high-latitude or high-elevation mountain belts (Egholm et al., 2009; Herman et al., 2014), as long as ice is not frozen to the bedrock
(Thomson et al., 2010). In non-glaciated environments, rainfall intensity plays an important role in controlling erosion (Roe et al., 2005), but there is growing evidence that variability in rainfall may be as important as mean precipitation in limiting or enhancing the rate of surface erosion by mountain streams and rivers (Lague and Hovius, 2005; DiBiase and Whipple, 2011). Variations in rainfall also affect the rate of chemical erosion as water availability is, with temperature, one of the main controls on silicate weathering (Dixon et al., 2009; Maher and Chamberlain, 2014). The thawing and freezing of soil-mantled slopes is also known to highly amplify the rate of soil creep (Anderson, 2002), implying that variability in temperature at or near freezing point must affect the rate of transport of chemically weathered rocks. Vegetation type and cover are also a function of climate (and elevation) and there is now mounting evidence that vegetation and erosion are linked (Hupp and Osterkamp, 1996; Dosseto et al., 2010), providing another potential, and so far poorly studied, link between erosional efficiency and climate. 
The climate of the late Cenozoic and of the Quaternary in particular is dominated by large variations in continental ice cover both near the poles and in regions of elevated topography, which are controlled by variations in the Earth's orbital parameters, the so-called Milankovitch cycles (Milankovitch, 1941). Other aspects of the Earth's climate are also known to vary between glacial and non-glacial periods, such as the strength of the monsoon, or the latitudinal distribution of precipitation (Rossignolstrick, 1983; Prell and Kutzbach, 1987; Demenocal and Rind, 1993; Clemens et al., 1991, 1996). There is clear evidence that since the onset of large amplitude, $100 \mathrm{ka}$ period glacial cycles approximately $1 \mathrm{Ma}$ ago, glacial erosion is strongly enhanced during periods of extended ice cover (Valla et al., 2011; Herman et al., 2014), but other potential effects of climatic variations at Milankovitch periods on the erosional response of mountain belts, such as variations in rainfall intensity and/or variability, have not been extensively studied, potentially because of the large difference between the Milankovitch orbital periods and the typical tectonics/erosion timescales ( $\geq 1 \mathrm{Ma}$ ).

The response of geomorphic systems to cyclic climate variations at either longer or shorter periods, has, however, been the subject of several studies. Paola et al. (1992) and Willgoose $(1994,2005)$ showed that, under the assumption that sediment transport rate is related to slope and runoff, the response of an equilibrium system (i.e., having reached a steady-state form by balancing uplift and erosion) to a sinusoidal variation in rainfall depends on the period of forcing in comparison to the response time of the system (the time it takes to reach equilibrium). If the forcing is much faster than the response time, the system is constantly out of equilibrium; when the forcing is slow, the system is able to remain at equilibrium; for intermediary forcing timescales, the geomorphic system's response lags the rainfall variations. Humphrey and Heller (1995) computed the response of a geomorphic system composed of an eroding mountain (obeying a linearized version of the stream power law) and a depositional foreland to demonstrate that an oscillating forcing (in precipitation for example) causes cyclic sedimentation patterns that show maximum amplitude at the contact point between the erosional and depositional systems. They also note that the time delay between forcing and response is mostly a function of the system size, not the period of forcing, and that the response is always damped in comparison with the forcing.

Using a more complex model combining the effects of soil formation and transport on hillslopes to the transport and erosion by river channels, Tucker and Slingerland (1997) demonstrated that cycles in runoff intensity cause a nonlinear response of geomorphic system, which strongly depends on the period of the cycles in comparison with the response time of the system. They also confirmed the results of Rinaldo et al. (1995), who showed that drainage density varies during climate cycles as the balance between fluvial and hillslope transport and erosion evolves through time.
Using a diffusive model for fluvial sediment transport by rivers, Castelltort and Van Den Driessche (2003) showed that Milankovitch-period variations in sedimentary supply from a high-relief, fast-eroding source (the mountain) are strongly buffered and therefore unlikely to be preserved in the depositional record. Using a more sophisticated model that includes the effect of grain size on transport capacity, Armitage et al. (2011) demonstrated that variability in rainfall is mostly imprinted in the sedimentary record as variations in grain size and its distribution with distance to the source. In a more recent study, Simpson and Castelltort (2012) argue that highfrequency rainfall cycles can be propagated and amplified to sedimentary basins if one assumes a potentially strong feedback between discharge and channel gradient. Similarly, but focusing on Milankovitch cycles timescales, Godard et al. (2013) demonstrated, using a surface processes model that combines fluvial erosion and hillslope processes, that geomorphic systems behave as "forced oscillators" where climate forcing is amplified in the sedimentary response at a relatively specific range of frequencies, although their response to the relatively short-period Quaternary climate variability is strongly damped when diffusive processes become dominant over river incision.

Here we present an analytical solution to the stream power law equation forced by climate-driven cycles in precipitation. We show that it is a natural behavior of this equation to predict an amplification and introduce a time lag between forcing and response. We then use a simple numerical solution of the same equation to fully appreciate the response of a fasteroding tectonic system to periodic perturbations in precipitation, with a particular focus on forcing at the Milankovitch periods. We then interpret these solutions in terms of the consequences they have on the behavior of natural systems and their response to cyclic rainfall variability at a range of forcing periods.

\section{The stream power law}

We will assume that bedrock incision is the dominant mode of erosion in an active mountain belt. Under the assumption that fluvial erosion can be represented by the stream power law (Howard, 1994) and that drainage area increases as a power of the distance to the water divide (Hack, 1957), the evolution of bedrock height, $h$, as a function of time is given by the following partial differential equation, or PDE (see Appendix for a detailed derivation):

$$
\frac{\partial h}{\partial t}=U-K v^{m}(L-x)^{m p}\left(\frac{\partial h}{\partial x}\right)^{n},
$$

where $L$ is the length of the river channel, $U$ is rock uplift, $v$ is precipitation rate and $K, n, m$ and $p$ are constants. The distance $x$ is measured from base level $(h(x=0)=0)$. Let us note that, as drainage area tends towards zero at the divide, erosion rate is arbitrarily nil at $x=L$. This is commonly handled by defining a critical slope, $S_{\mathrm{c}}$, beyond which the stream 
power law is no more valid and colluvial and hillslope processes become dominant (Whipple and Tucker, 1999). The slope $(n)$ and area $(m)$ exponents in the stream power law are not well constrained. Their commonly accepted ranges are $0.2<m<0.8$ and $0.5<n<2$. The ratio $m / n$ controls the concavity of stream profiles that have reached an equilibrium between uplift and erosion (see Eq. A11 in the Appendix) and, where estimated, it ranges between 0.4 and 0.6. Independently, $p$, the exponent in Hack's law relating drainage area to distance to the divide can be extracted from digital elevation model analysis; its commonly accepted value is close to 2 .

\section{Response to precipitation change}

In the Appendix, we show that this equation can be written in dimensionless form as follows:

$\frac{\partial h^{\prime}}{\partial t^{\prime}}=1-\left(1-x^{\prime}\right)^{m p}\left(\frac{\partial h^{\prime}}{\partial x^{\prime}}\right)^{n}$,

where $\quad x^{\prime}=x / L, \quad h^{\prime}=h / H, \quad t^{\prime}=t / \tau, \quad$ and $H=\left(\frac{U}{K v^{m}}\right)^{1 / n} \frac{L^{1-m p / n}}{1-m p / n}$ and $\tau=H / U$. We also show that the variation in normalized height, $\delta h^{\prime}$, resulting from a small perturbation in precipitation, $\delta v^{\prime}$, obeys the following PDE:

$\frac{\partial \delta h^{\prime}}{\partial t^{\prime}} \approx-m \delta v^{\prime}-\frac{n}{1-m p / n}\left(1-x^{\prime}\right)^{m p / n} \frac{\partial \delta h^{\prime}}{\partial x^{\prime}}$.

The first term of the right-hand side of the equation corresponds to the direct response of the system to the perturbation (it is directly and linearly proportional to $\delta v^{\prime}$ ), whereas the second term expresses how the resulting change in slope, $\frac{\partial h^{\prime}}{\partial x^{\prime}}$, modifies the response of the system to future perturbation.

In the Appendix, we show that there exists an approximate solution to this equation, which yields the response of the system to a small periodic perturbation in precipitation rate, $v=v_{0}+\delta v_{0} \sin \left(\frac{2 \pi t}{P}\right)$, in the form of the corresponding variation in the sedimentary flux, $Q=Q_{0}+\delta Q_{0}$, i.e., the erosion rate integrated over the channel length. The solution can be expressed as

$\frac{\delta Q_{0} / Q_{0}}{\delta \nu_{0} / \nu_{0}}=\frac{\delta Q^{\prime}}{\delta v^{\prime}}=G \sin \left(\frac{2 \pi(t+\theta)}{P}\right)$,

where $G$ is a dimensionless gain and is given by

$G=\frac{2 \pi \tau m / P}{\sqrt{(2 \pi \tau / P)^{2}+\left(\frac{m p}{1-m p / n}\right)^{2}}}$

and $\theta$ is a phase shift, or time lag, between the forcing (the perturbation in precipitation rate) and the response (the resulting perturbation in sedimentary flux), given by

$\theta=\frac{P}{2 \pi} \tan ^{-1}\left(\frac{P}{2 \pi \tau} \frac{m p}{1-m p / n}\right)$.

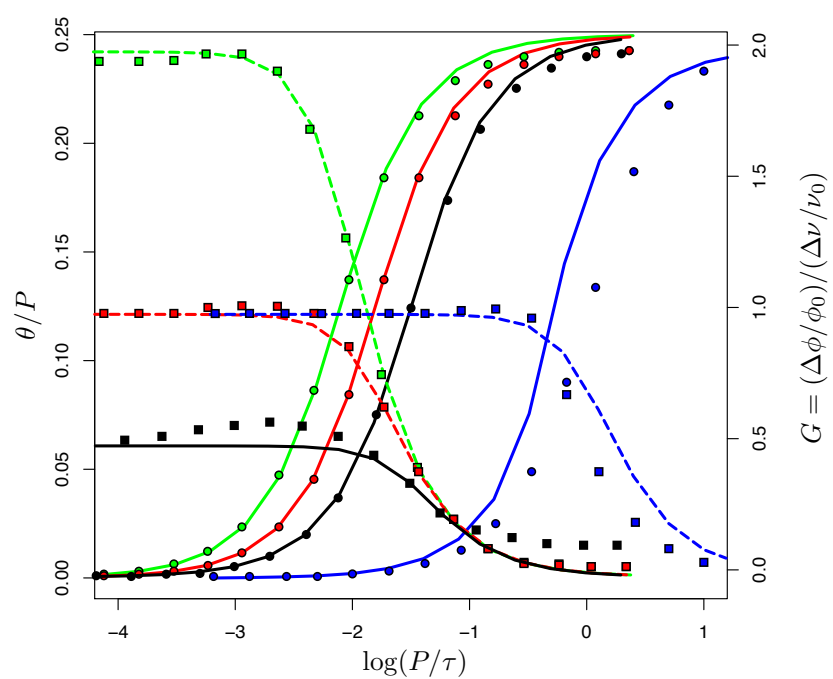

Figure 1. Predictions of the quasi-analytical solution (solid and dashed lines) and the numerical simulation (squares and circles). The solid lines and circles represent the time lag (divided by the forcing period, $P$ ) and the dashed lines and squares represent the gain, both as a function of the forcing period, $P$ (normalized by the characteristic time of the system, $\tau$ ). The green, red and blue lines/symbols correspond to values of $(m, n)$ equal to $(0.5,1)$ and $(1,2)$ and $(2,4)$, respectively, such that $m / n=1 / 2$ in all three cases. The blue lines/symbols correspond to the case where $(m, n)=(1,3)$, i.e., $m / n=1 / 3 \neq 1 / 2$, which explains why, in that case, the quasianalytical solution is less accurate.

$P$ is the period of forcing and $\tau$ is the characteristic time of the system, i.e., the time it takes for erosion to balance uplift $(\tau=H / U)$. Note that this solution is only valid for values of the ratio $m p / n$ close to unity (see Appendix).

The predicted time lag and gain are shown in Fig. 1 as functions of the period of the perturbation, for various values of the exponent $m$ and $\frac{m p}{1-m p / n} \approx 1$. We see that for very short periods, i.e., in comparison with the characteristic timescale of the system $(P \ll \tau=H / U)$, the sedimentary flux is in phase with the perturbation. This is because the channel geometry does not have the time to respond to the perturbation in precipitation rate. As the forcing period increases, the time lag grows until it reaches a quarter of the forcing period and the two signals are completely out of phase. This can be derived from Eq. (6), where

$$
\begin{aligned}
& \lim _{P \ll \tau} \theta=0 \\
& \lim _{P \gg \tau} \theta=P / 4 .
\end{aligned}
$$

For intermediary periods $(\tau / 100<P<\tau)$, the system is out of phase, with the sedimentary response lagging behind the climate forcing. These results are in agreement with the qualitative analysis of Willgoose (1994) based on the results of a landscape evolution model where sediment transport is assumed proportional to slope and surface runoff (proportional to precipitation and drainage area). Our results also show 
that the time lag increases with $m$ (compare the red curve corresponding to $m=1$ with the black curve corresponding to $m=2$ and the green curve corresponding to $m=0.5$ in Fig. 1).

We note also that the gain decreases with the forcing period. The gain is maximum and equal to $m$ when the forcing period is small compared to $\tau$ and it tends towards zero when the forcing period is much larger than $\tau$. This can be derived from Eq. (5):

$$
\begin{aligned}
& \lim _{P \ll \tau} G=m \\
& \lim _{P \gg \tau} G=0 .
\end{aligned}
$$

In this latter situation $(P \gg \tau)$, the channel has the time to adjust to the variable precipitation and remains at steady state such that the sedimentary flux perfectly balances the uplift rate, $U$, and there is no perturbation (the gain is nil).

It is worth noting that this behavior is similar to the response of a general linear system with finite memory as described by Howard (1982, see his Fig. 1) while considering the general response of geomorphological systems to step or periodic forcing. Although clearly derived from a non-linear equation, our solution could be regraded as the application of this general principle to bedrock channel incision parameterized by the stream power law.

\section{Numerical solution}

To test the accuracy of this approximate solution, we have solved the stream power law using the following implicit finite difference scheme (Braun and Willett, 2013):

$$
\begin{aligned}
h_{i}(t+\Delta t)= & h_{i}(t)+U \Delta t-K \Delta t v^{m}(L-x)^{m p} \\
& \left(\frac{h_{i}(t+\delta t)-h_{i-1}(t+\delta t)}{\delta x}\right)^{n} .
\end{aligned}
$$

The non-linear dependence of erosion rate on slope (when $n \neq 1$ ) was dealt with by using a Newton-Raphson iterative scheme (Braun and Willett, 2013). We imposed the uplift rate and the mean precipitation rate. We adjusted the constant $K$ such that the resulting steady-state topography reaches a set value, $H_{\max }$. Note that the value of the mean precipitation rate is not important, as it appears as a multiplier of the constant $K$ in the stream power law. The model was run to steady state and a sinusoidal variation in precipitation rate was then imposed of amplitude equal to one-tenth of the mean precipitation rate. The amplitude of this perturbation is of no importance to the solutions we present, as long as it remains small in comparison with the mean precipitation rate. Increasing the amplitude of the perturbation towards values close to the assumed mean precipitation causes the time lag to increase and the amplification to decrease, but the characteristics of the solution remain unchanged. The channel length was set to $200 \mathrm{~km}$ but its value does not influence the solution either, implying that the response of an incising river to a perturbation in precipitation rate does not depend on its size or the size of its catchment. This is a consequence of using a value of $m p / n \approx 1$.

We computed the gain as the ratio of the amplitude of the variations in sedimentary flux normalized by the mean sedimentary flux (at steady state) by the amplitude of the imposed variations in precipitation rate normalized by the mean precipitation rate. We also computed the phase shift between the imposed precipitations and the computed sedimentary flux by performing a cross-correlation between the two signals. The results are also shown in Fig. 1 where they are compared to the semi-analytical solution for different combinations of the parameters $m, n$ and $p$.

The first interesting result is that the numerical solution is almost identical to the analytical solution when $m p / n \approx 1$, implying that the analytical solution is a good approximation of the general behavior of the system. For values of the exponents such that $m p / n \neq 1$, the analytical solution is not so accurate as shown in the case where $m=1, n=3$ and $p=2$ (blue curve in Fig. 1), but the shape of the solution is very similar with the analytical solution clearly overestimating the time lag. In all cases, the numerical solution predicts a time lag between climate and the resulting erosional response that is a function of the forcing period, reaching a maximum of $P / 4$ when the forcing period is similar to the characteristic time, $\tau$. Similar to the analytical solution, the gain, $G$, or ratio of the relative variation in sedimentary flux (normalized by its steady-state value) to relative variation in precipitation (normalized by its steady-state value), scales with $m$ for periods that are small compared to the characteristic timescale of the system and tends towards zero for longer periods.

To better understand the solution and thus the behavior of the system, we show in Fig. 2 snapshots of the evolution of the models in terms of the departure in erosion rate from the mean (steady-state) value. We selected the model run in which $n=4, m=2, p=2, P=100 \mathrm{ka}$ and $U=6 \mathrm{~mm} \mathrm{a}^{-1}$. We recognize that the values of $m$ and $n$ we selected are large and likely to be outside the range of acceptable values, but this choice produces a clear time lag and amplification of the erosional signal that we can more easily use to illustrate the behavior of the system. The solution shows the propagation of damped waves in erosion rate (Fig. 2b) with the erosion rate varying locally by as much as $50 \%$ of the imposed mean value (here $6 \mathrm{~mm} \mathrm{a}^{-1}$ ). As rainfall increases at the beginning of a cycle (black curve in Fig. 2b), the incision rate increases near the base level. The maximum in anomalous erosion rate propagates up the profile (blue curve in Fig. 2b) until the precipitation rate starts to decrease. The erosion rate decreases then drastically near the base level (red curve in Fig. 2b), and a similar but opposite-sign wave of reduced erosion rate propagates towards the head of the channel (purple curve in Fig. 2b). The cycle then repeats itself. Note that the height of the river profile is also affected by similar topographic waves but, interestingly, whereas the predicted erosion rate can vary by as much as $50 \%$ locally, the topographic "waves" never exceed $100 \mathrm{~m}$ in amplitude (i.e., $<2 \%$ of the maximum to- 

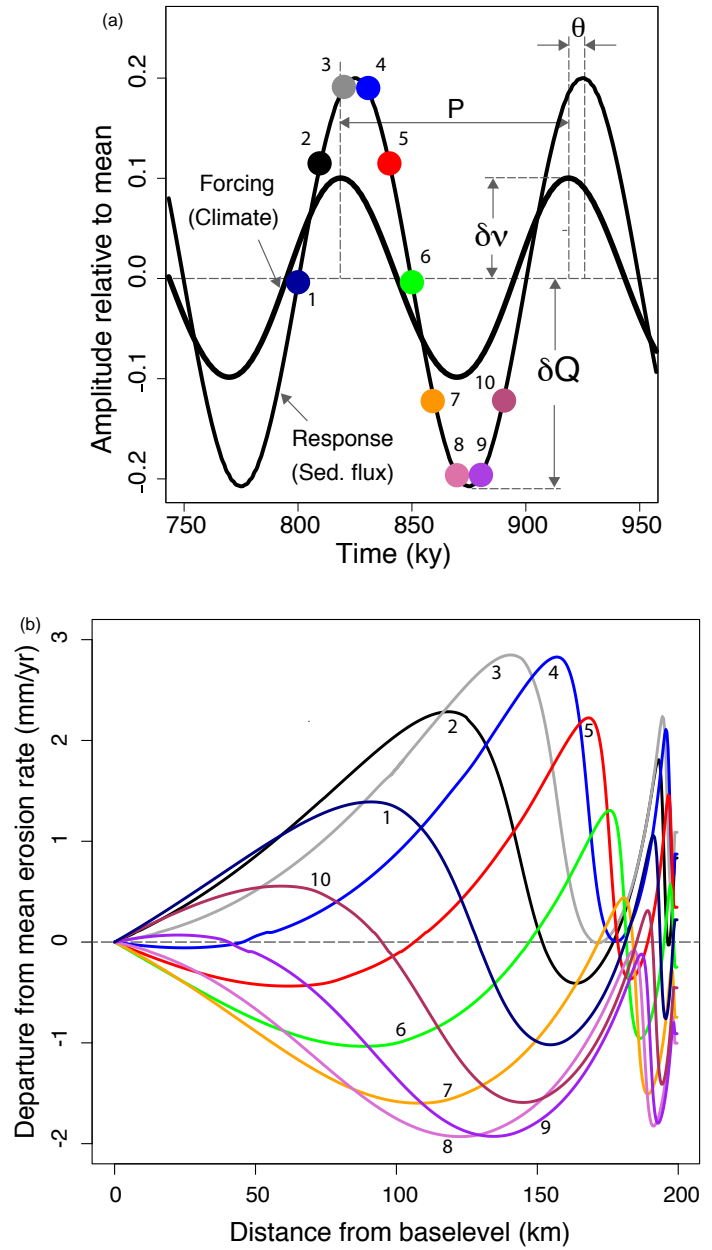

Figure 2. (a) Evolution of precipitation (climate) and the resulting sedimentary flux through a couple of imposed cycles (here at $100 \mathrm{ka})$ derived from the numerical solution of the stream power law for exponent values of $n=4, m=2$ and $p=2$. The phase lag $\theta$ and the relation between the variations in precipitation $\delta v$ and the resulting variations in sedimentary flux $(\delta Q)$, i.e., the gain, are also shown. (b) Erosion rate anomaly along the stream profile at various times during a rainfall cycle; each curve corresponds to a time that is indicated by a circle of the same color in (a).

pography), anywhere along the profile. The wavelength of these waves is such that the topographic perturbation they cause is likely to be almost undetectable.

The formation of these waves corresponds to the response of a system at equilibrium to a small perturbation. If the rate of change of the perturbation is rapid (in comparison to the characteristic time of the system), the system does not have the time to adjust and the perturbation in rainfall results in an instantaneous and proportional response in erosion rate. Consequently, the erosional response is in phase and in proportion to the perturbation (here amplified by the power $m$ to which the discharge, and thus rainfall, is raised in the stream power law). On the contrary, when the perturbation rate is

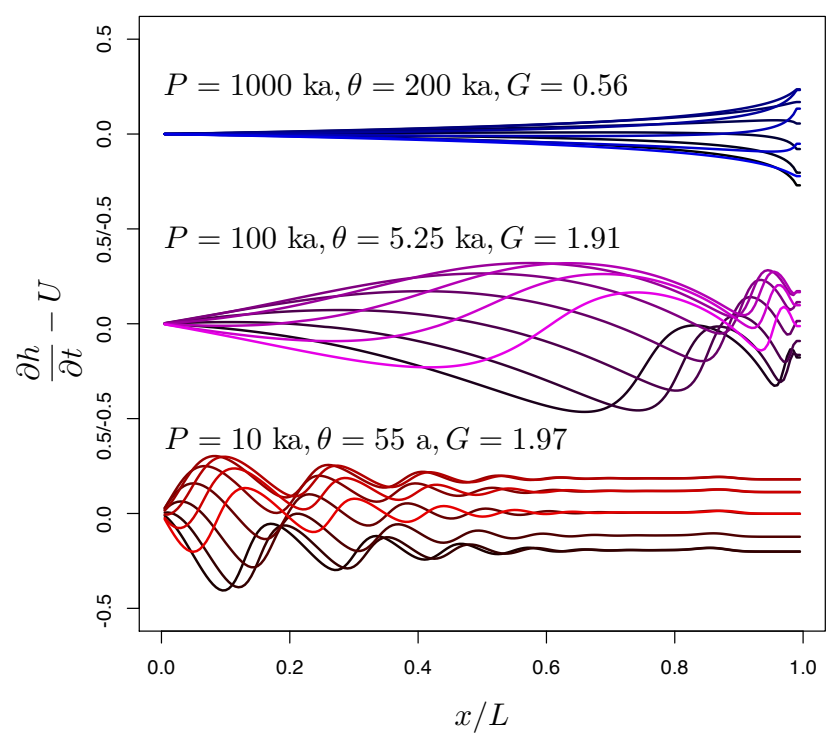

Figure 3. Computed normalized erosion rate $\left(\frac{\partial h}{\partial t} / U\right)$ as a function of the normalized distance $(x / L)$ along the river profile for different values of the forcing period, $P$. Each curve in a given set corresponds to a selected snapshot during a rainfall cycle. Top (blue) curves, middle (purple) curves and bottom (red) curves correspond to $P=1000,100$ and $10 \mathrm{ka}$, respectively. $n=4, m=2$ and $p=2$ in all three model runs.

very slow (in comparison to the characteristic time of the system), the system is able to adjust, the system remains at or close to steady state and the integrated rate of erosion remains constant and equal to the imposed uplift rate. These two end-member behaviors are shown in Fig. 3 (blue and red curves), as well as the case where the forcing period is similar to the characteristic time of the system (purple curves). We see that, for long forcing periods, the response is strongly damped as the system is able to change its shape (slope) and adjust to the variation in precipitation rate such that erosion rate remains almost equal to uplift rate along the entire length of the river profile; the only remaining anomaly in erosion rate is near the headwaters of the stream and is therefore strongly out of phase. For short forcing periods, the perturbation propagates rapidly over the entire length of the profile such that it is able to offset the erosion rate over its entire length, therefore leading to a large amplitude response that is, however, in phase with the forcing.

In Fig. 4, we show the geometry of these waves/perturbations at the start of a precipitation cycle (corresponding to point 1 on Fig. 2a) for a range of values of the exponents $m$ and $n$. We kept all other parameters at constant values, i.e., $U=6 \mathrm{~mm} \mathrm{yr}^{-1}$ and $P=100 \mathrm{ka}$. As usual the $K$ parameter is adjusted such that the resulting steady-state river profile maximum height is $6000 \mathrm{~m}$. We note that, to first order, the wavelength of these waves determines the time lag -i.e., the shorter the wavelength, the 


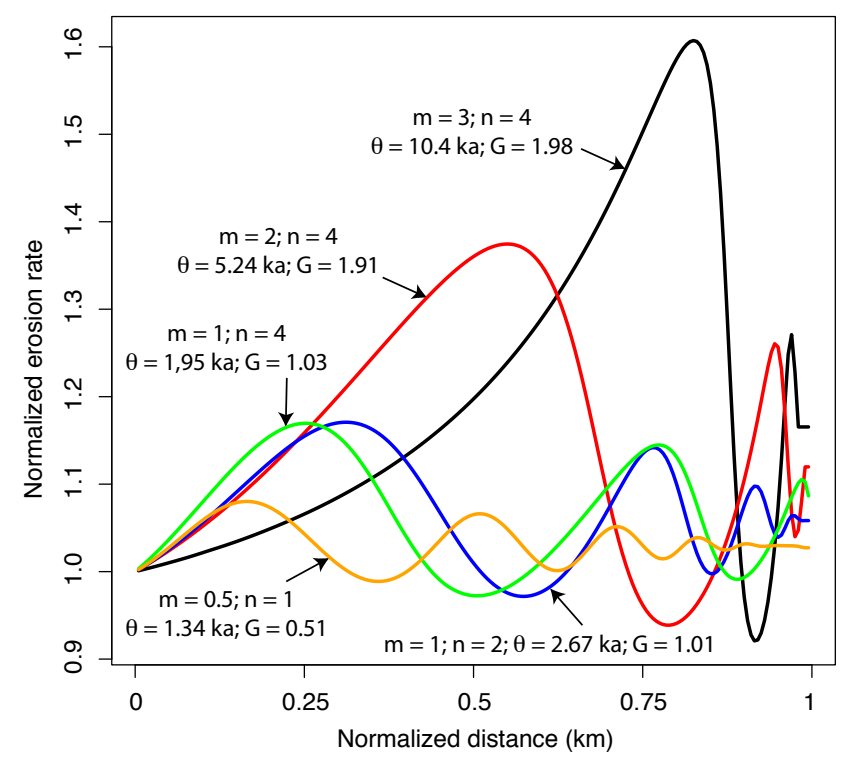

Figure 4. Computed normalized erosion rate $\left(\frac{\partial h}{\partial t} / U\right)$ as a function of the normalized distance $(x / L)$ along the river profile for a forcing at $P=100 \mathrm{ka}$ and for various values of the exponents $m$ and $n$; for each run we indicate the value of the computed time lag, $\theta$, and gain, $G$.

shorter the time lag - whereas their amplitude determines the gain.

Finally, we performed a large number of simulations, keeping the uplift rate constant at $6 \mathrm{~mm} \mathrm{a}^{-1}$, but varying $m$, $n$ and $P$. The results are shown in Fig. 5. For small forcing periods (Fig. 5a; $P=1 \mathrm{ka}$ ) compared to the characteristic time, the offset is nil and the gain is directly proportional to $m$ (Fig. 5a). For intermediate values of the forcing period (Fig. 5b and c), which we arbitrarily selected to correspond to the 41 and $100 \mathrm{ka}$ Milankovitch periods, the gain remains proportional to $m$, especially for values of $m$ and $n$ that are close to the limit $m / n=0.5$ (or $m p / n=1$ ). If we assume that the ratio between $m$ and $n$ is well constrained, this implies that the gain is also proportional to $n$. This simple relationship breaks down for large forcing periods (Fig. 5d) as the gain tends towards zero, independently of $m$ or $n$.

The time lag, $\theta$, is nil for small values of the forcing period. For intermediate values of the forcing period (Fig. 5a), it increases with $m$ as well as with $n$, such that the increase in time lag along the $m / n=0.5$ line is relatively small: it varies between 250 and 1000 a for $P=41 \mathrm{ka}$ and between 1000 and 5500 a for $P=100 \mathrm{ka}$ (Fig. $5 \mathrm{~b}$ and c). These contour plots also show that the time lag increases mostly as the ratio $m / n$ tends towards 1 (the thick black diagonal line).

\section{Discussion}

Our solutions demonstrate that time lags are a natural response of erosional systems to climate (rainfall) variability if they obey and are controlled by the stream power law. The sedimentary flux responds to an external climate forcing variable precipitation - in a way that depends on how the forcing period compares to the characteristic timescale of the system, $\tau$, which is itself proportional to mountain height and inversely proportional to mean uplift rate. When the forcing period, $P$, is within the range $\tau / 100<P<\tau$, a substantial time lag is predicted in the erosional response to a cyclic precipitation pattern (see Fig. 1). Time lags associated with forcing at Milankovitch periods should therefore be measurable in most orogenic systems that have a characteristic timescale of a few million years (Whipple and Meade, 2006) and, particularly, in fast uplifting/eroding mountain belts, such as the Southern Alps in New Zealand or the Taiwan orogen, which both experience uplift and erosion rates of the order of $10 \mathrm{~mm} \mathrm{a}^{-1}$.

We also predict that the erosional response is multiplied by a factor $m$, the area exponent in the stream power law, for forcing at periods smaller than $\tau$. Although $m$ is likely to be smaller than unity, it is possible that, if $m>1$, the sedimentary signal be enhanced, which may explain the strong imprint that Milankovitch cycles have on the sedimentary record (De Boer and Smith, 1994) despite the relatively small changes in both solar insulation and temperature that are associated with the corresponding variations in the Earth's orbital parameters. At long forcing periods (compared to $\tau$ ), the gain tends towards zero, inhibiting detection of the time lag.

We have also shown that the erosive response of a river to a change in precipitation rate does not depend on its length. This ensures that all streams and catchments in a given mountain belt respond in a synchronous manner. It is a direct consequence of the stream power law combined with Hack's law. To test whether this still holds when taking into account the complex geometry and varied topology of river networks, we have used the plan-form two-dimensional landscape evolution model FastScape (Braun and Willett, 2013) to perform a simulation similar to the 1-D models presented here above. We used the following model parameters: $n=4$, $m=2, K=3 \times 10^{-14} \mathrm{~m}^{1-3 m} \mathrm{a}^{-1-m}$ and $U=6 \mathrm{~mm} \mathrm{a}^{-1}$ to allow for a direct comparison with the results shown in Fig. 2. The solution is shown in Fig. 6 and is also provided as a small animation (see Supplement).

On the one hand, and as in the 1-D model, the computed topography (Fig. 6d-f) remains relatively unchanged throughout the precipitation cycle with local variations of the order of a few tens of meters only. On the other hand, the erosion rate (Fig. 6a-c) changes dramatically from step to step. The model predicts a wave of erosion rate in each of the model catchments. The wave propagates at the same rate in all catchments, regardless of their size or geometry (panels a to c) demonstrating that Hack's law, used in the 1-D analytical solution (Eq. 1) and in the 1-D numerical model (Fig. 2), is a good approximation to the topology of catchments and the plan-form relationship between drainage area 

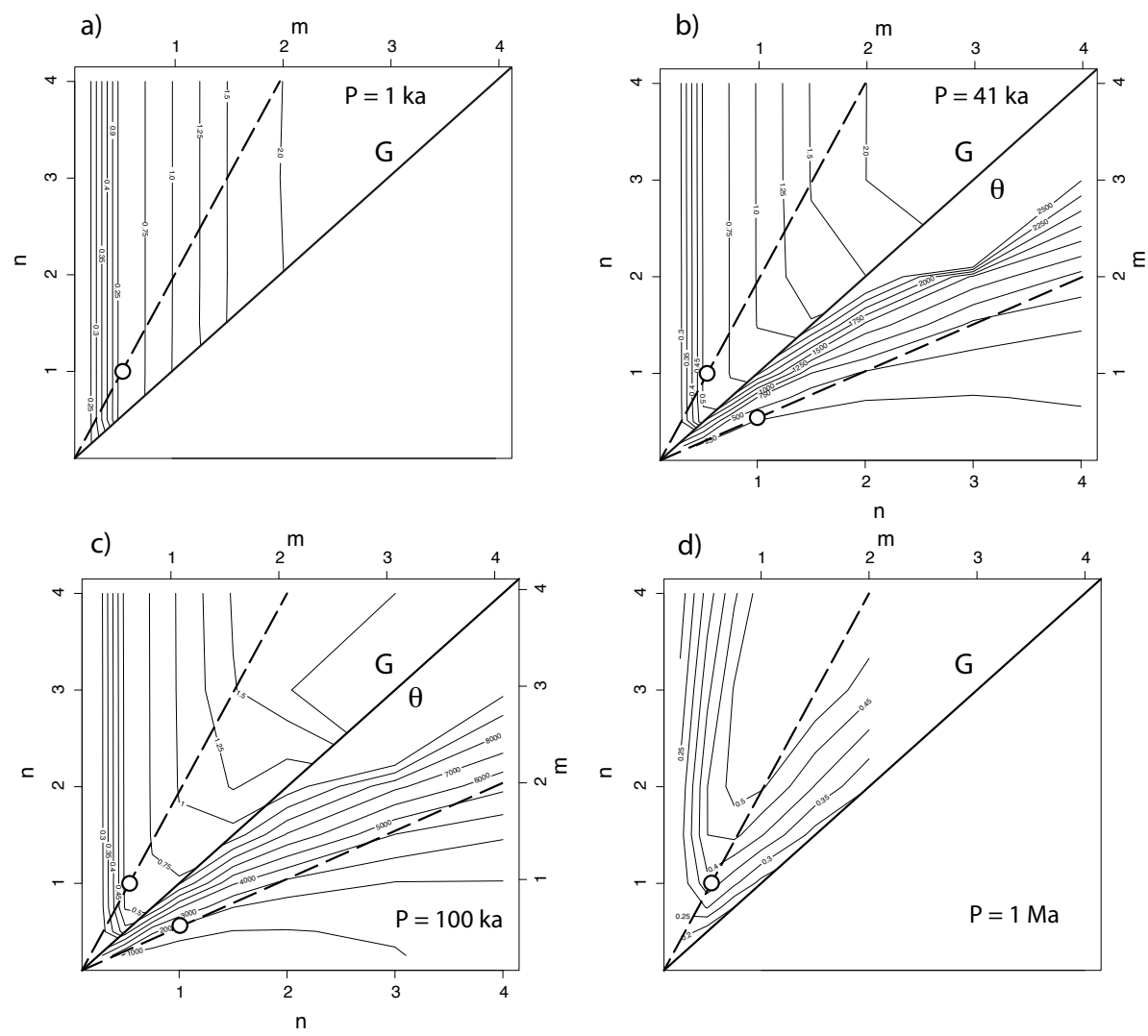

Figure 5. Contour plots of computed gain $G$ (upper left half of each panel), and time lag $\theta$ (lower right half of $\mathbf{b}$ and $\mathbf{c}$ ), as a function of the stream power law exponents $m$ and $n$ for different forcing periods: (a) $1 \mathrm{ka}$, (b) $41 \mathrm{ka}$, (c) $100 \mathrm{ka}$ and (d) $1 \mathrm{Ma}$. $U$ is $6 \mathrm{~mm} \mathrm{a}$ and $p=2$ in all model runs. Contour labels for $\theta$ are in years; $G$ is a dimensionless quantity. The dashed lines correspond to $m / n=0.5$, a commonly accepted value derived from river profile concavity measurements. The circles correspond to the preferred values for $n(=1)$ and $m(=0.5)$. Gain and time lag were only computed for values of $n \geq m$.

and distance to the divide. We also note that drainage geometry and, a fortiori, drainage density does not change during a climate cycle. This is contrary to the results of simulations performed by Rinaldo et al. (1995) and Tucker and Slingerland (1997) implying that hillslope processes (not included in the FastScape model runs presented here) must control drainage density in a varying climate.

Another important outcome of our study is that, although the response of the stream power law to small cyclic variations in precipitation produces nearly undetectable changes in river longitudinal profiles, the erosional waves they trigger are measurable and, potentially, amplified (depending on the value of $m$ ). These waves could cause in situ measurements of erosion rate by cosmogenic isotope methods, for example, to be strongly variable both in space and time, rendering estimates of local or catchment-averaged exhumation rate rather difficult.

A direct comparison of our results (Fig. 1) with those of Godard et al. (2013) (see their Fig. 2) shows that the amplification of the climate cycles in the sedimentary record near the "forced oscillator" periods they evidenced is reproduced by our model; it corresponds to the slight increase in the gain (or amplitude response) that is seen on all curves presented in Fig. 1 ahead of the transition to low gain values. Note that this slight increase in gain is relatively subtle compared to the main one we evidence here, which scales with $m$.

Unlike Godard et al. (2013), however, we did not include in our computations the effect of the hillslope response to variations in stream incision rate caused by rainfall cycles. Here, we focused our attention on the stream power law representing bedrock incision which we considered as the main controlling agent on the rate of landscape evolution in active mountain belts. In a mountain that has reached steady state between fast uplift and erosion, it is likely that hillslopes are close to or at a critical state (slope) and should therefore respond almost instantaneously to variations in stream incision rate, at least for forcing periods of the order of a few tens of thousands of years (the Milankovitch periods, for example). For slowly uplifting areas, this might not be the case and further work should concentrate on including a reasonable representation of hillslope process but also of sediment transport capacity by rivers in the calculations presented here. 


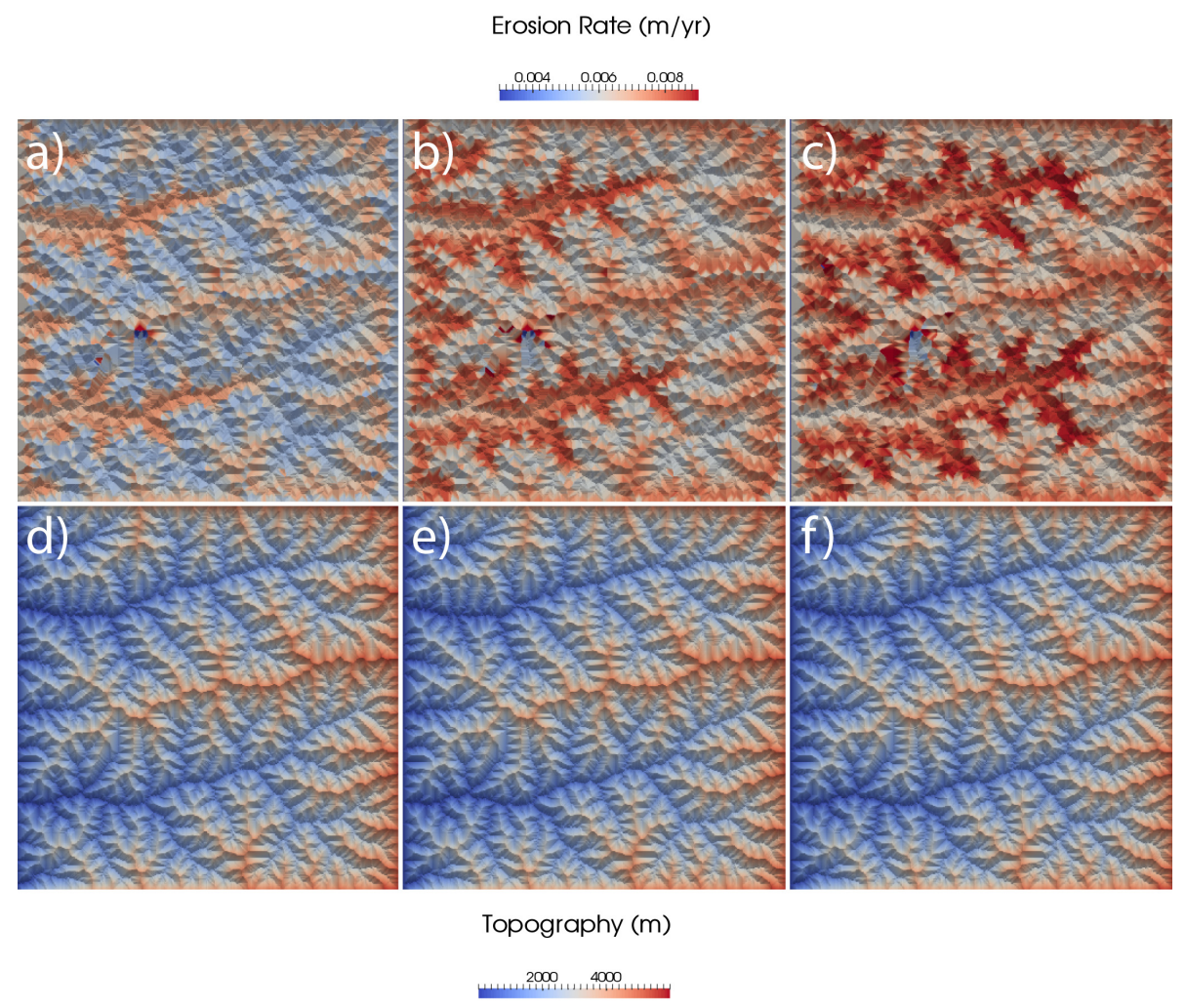

Figure 6. Evolution of (a)-(c) the erosion rate and (d)-(f) the topography predicted by the FastScape landscape evolution model showing the propagation of waves of erosion during an imposed precipitation cycle (a and $\mathbf{d}$ correspond to the time when precipitation rate is at its mean value; $\mathbf{b}$ and $\mathbf{e}$ correspond to the time when precipitation rate has increased to half of its maximum amplitude, i.e., one-eighth into the precipitation cycle; $\mathbf{c}$ and $\mathbf{f}$ correspond to the time when precipitation rate has increased to its maximum amplitude, i.e., one-quarter into the precipitation cycle). Note the synchronism between all drainage basins, regardless of their drainage area and/or geometry.

Observations of a potential time lag between climate forcing and the erosional response of an active tectonic area are rare. In a recent paper, Gourlan et al. (2014) argue that they observe a time lag between $\delta^{18} \mathrm{O}$ and $\epsilon_{\mathrm{Nd}}$ records derived from a well-studied ODP site (ODP 758) located in the southern part of the Bengal Fan (Gourlan et al., 2010). This is, potentially, an appropriate site to observe changes in continental riverine input related to changes in the erosional flux from the Himalayas. The data sets they use are rather unique for they provide records of both climate and $\epsilon_{\mathrm{Nd}}$ (a proxy for the intensity of the riverine sedimentary input from Himalayan rivers) at high resolution and on the same samples. This allows for a direct time correlation between the two data sets, even if the exact age of each sample is only constrained by correlating the local $\delta^{18} \mathrm{O}$ signal with globally averaged sea surface temperature data (Gourlan et al., 2010). A careful spectral analysis of the two signals shows the existence of a well-defined time lag between $\delta^{18} \mathrm{O}$ and $\epsilon_{\mathrm{Nd}}$ at Milankovitch periods, which increases with the forcing period. This time lag is 1000,2000 and $7000( \pm 500)$ years at the 23, 41, and $100 \mathrm{ka}$ Milankovitch periods, respectively. Gourlan et al. (2014) argue that the delay between temperature changes recorded by $\delta^{18} \mathrm{O}$ and the erosion flux out of the
Himalayas recorded by $\epsilon_{\mathrm{Nd}}$ must be a consequence of how the variability in summer monsoonal rainfall affects erosion in the Himalayas. Estimates from global circulation models suggest that Indian monsoonal rainfall intensity varies in phase with temperature at orbital cycle periods (Braconnot, 2004) with an amplitude of a $1-2 \mathrm{~mm} \mathrm{day}^{-1}$, which is approximately $10 \%$ of the present-day precipitations.

Using the numerical model described above, we searched through parameter space to find the best fitting model parameters that would provide a close fit to the observed time lags. We varied $m, n, p$ and $U$ and, for each run, adjusted $K$ so that the steady-state maximum mountain height is $6000 \mathrm{~m}$. There is no single solution to this search. In Fig. 7, we show the fit of three model runs corresponding to various values of the model parameters.

We combined the solutions of many model runs performed at the three Milankovitch periods (23, 41 and $100 \mathrm{ka}$ ) (Fig. 8) but assuming a constant value of $U=6 \mathrm{~mm} \mathrm{a}^{-1}$ and $p=2$, to show that the range of acceptable $m$ and $n$ values defines a region in $[m, n]$ space (dark grey shaded area in Fig. 8) that is sub-parallel to the commonly accepted range for $m$ and $n$ defined by $m / n=0.5$. The corresponding gain factors range from 1 to 2 , depending on the value chosen for $m$. For 


\section{Comparison between observed and predicted time lags}

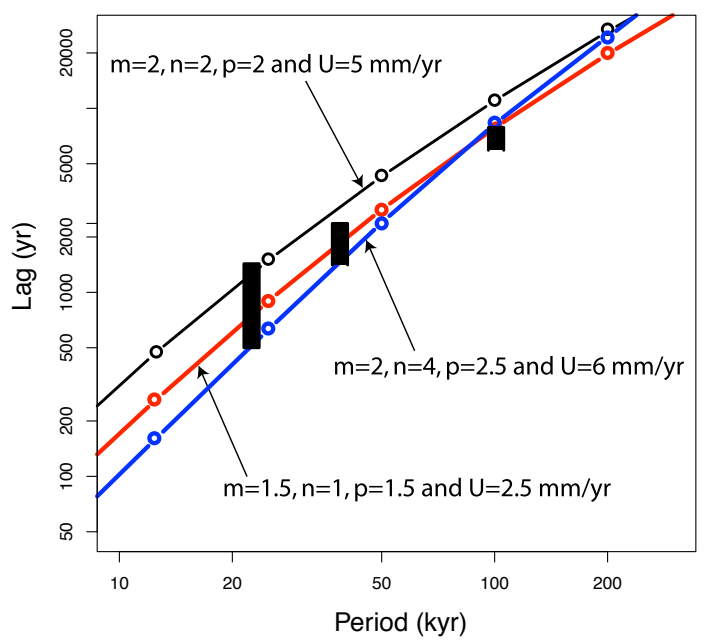

Figure 7. Comparison between observed time lags (i.e., derived from the spectral analysis of the geochemical proxies from Gourlan et al. (2014)) and the model predictions for different values of the $m, n$ and $p$ exponents and the assumed mean (steady-state) imposed uplift rate.

large $n$ values, the optimum $m / n$ ratio tends towards its more commonly accepted value of 0.5 .

We note, however, that only a small sub-ensemble of the best fitting values of the $m$ and $n$ model parameters (dark grey shaded area) are within the most commonly accepted ranges $(0.2<m<0.8$ and $0.5<n<2$, light grey-shaded area between light dashed lines). This could imply that the time lags observed between the geochemical data sets are not related to the erosional response of the Himalayas to a cyclic rainfall; the time lags could originate from the delayed transport in the Ganges plains, for example. The temporary storage of sediments in the Indian plains is best described by a transport limited or diffusive model (Castelltort and Van Den Driessche, 2003). However, to fit the constraint provided by the two geochemical signals (i.e., that the time lag increases with the forcing period), the diffusivity parameter needs to be scaled in an ad hoc fashion with the period of fluctuations, which is difficult to justify. Alternatively and if we recall that the value of the $m$ and $n$ exponents is poorly constrained and remains the subject of much debate (see the recent review paper by Lague (2014) on this subject), the observed time lags could be regarded as new, independent constraints on the value of the stream power law parameters.

Our best fitting models have values for $m$ and $n$ that are either very large, if imposed to be in the accepted ratio of 2, or that are not in this accepted ratio. If $n$ is indeed large, the response of the erosional system to changes in slopes is strong. Interestingly, it has been recently demonstrated that the exponent $n$ may depend on the variability of river discharge, and thus climate (Lague and Hovius, 2005). In a variable climate,

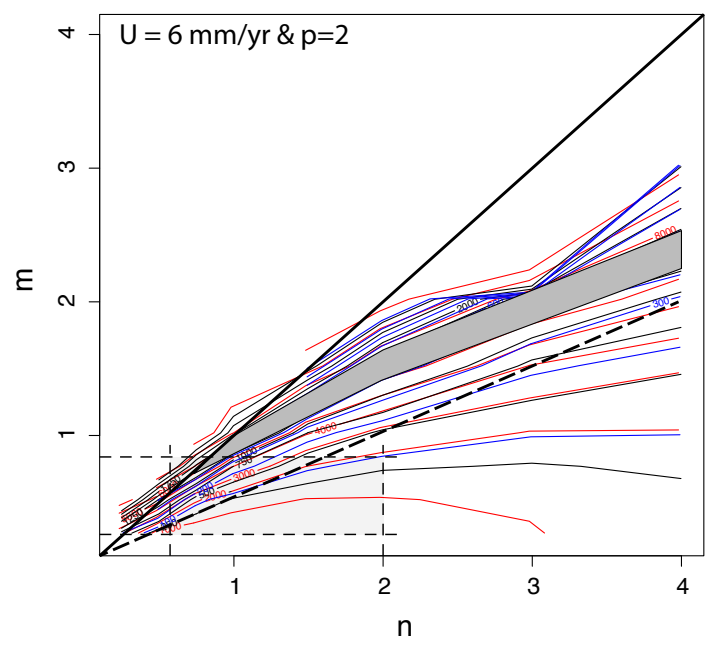

Figure 8. Contour plots of predicted time lags at the three Milankovitch periods (blue at $23 \mathrm{ka}$, black at $42 \mathrm{ka}$ and red at $100 \mathrm{ka}$ ) as a function of $m$ and $n$. The dark grey shaded area corresponds to the values of $m$ and $n$ that satisfy the three time lags derived from the spectral analysis of geochemical data from the Bengal Fan (Gourlan et al., 2014); the light grey shaded area corresponds to the range of commonly accepted values for $m$ and $n$.

$n$ and $m$ should have low values, with $n$ being close to unity, whereas, in locations where the climate is "steady", $n$ could be as large as 3 or 4 (Lague and Hovius, 2005). Alternatively, it could be that the ratio $m / n$ is not close to 0.5 , but this is difficult to reconcile with the very numerous observations of the steady-state concavity of river profiles (see Whipple and Tucker (1999), for example), unless one calls into question the existence of steady-state conditions between uplift and erosion.

\section{Conclusions}

Based on both analytical and numerical solutions to the stream power law, we have shown that it is a natural behavior of this equation to produce a time lag between cycling climate forcing and the resulting erosional response. The main finding is that the time lag depends on the forcing period. If the forcing period is small compared to the characteristic timescale of the tectonic system (i.e., the time it takes for the system to approach steady state between uplift and erosion), the time lag is small; conversely, if the forcing period is large, the time lag tends towards a quarter of the period (the response is exactly out of phase with the forcing). The second important finding is that the erosional response is amplified in comparison with the amplitude of the climate forcing in a direct proportion to the parameter $m$, the discharge exponent in the stream power law when the forcing period is small. For large value of the forcing period (in comparison with the characteristic timescale of the system), the amplification tends towards 0 , which means that very long-term 
variations in rainfall do not affect the erosional response of an active mountain belt and thus cannot be recorded, in the sedimentary record for example.

We have also demonstrated, based on simple 1-D and 2-D numerical landscape evolution experiments, that the response to climatic variations of an actively eroding mountain river, if it obeys the stream power equation, is independent of the size of its drainage basins, implying that, within a mountain belt, all rivers should respond in phase with each other to a periodic rainfall perturbation and, consequently, contribute constructively to the integrated sedimentary record.
We have shown that the response of a rapidly uplifting and eroding mountain belt to rainfall variations at Milankovitch periods can lag the climatic forcing by several thousands of years. This theoretical prediction should be used to interrogate the geological record and, potentially, test the validity of the stream power law as an adequate parameterization of fluvial erosion in active mountain belts. We have finally shown how geochemical signals could be used to extract such potential offsets under the assumption that they are adequate proxies for climate variability and the resulting erosional response. Potentially, such data sets could provide interesting and independent constraints on the slope and area exponents in the stream power law. We have also shown that the sedimentary flux fluctuations resulting from periodic rainfall variations can be amplified if $m>1$, which may explain the strong imprint that Milankovitch cycles have on the sedimentary record despite the relatively small changes in both solar insulation and temperature that are associated with the corresponding variations in the Earth's orbital parameters. 
Appendix A: Response of the stream power law to periodic rainfall

\section{A1 The stream power law}

Fluvial erosion in high-relief terrain is commonly parameterized by the stream power law (Howard, 1994):

$\frac{\partial h}{\partial t}=U-K v^{m} A^{m}\left(\frac{\partial h}{\partial x}\right)^{n}$,

where $h$ is the height of the bedrock, $U$ is rock uplift, $A$ is drainage area, $v$ is precipitation rate and $K, n$ and $m$ are constants. Drainage area is known to increase as a power of the distance to the water divide:

$A \propto(L-x)^{p}$

where $x=L$ corresponds to the position of the water divide with respect to the point, $x=0$, where the stream is held at base level:

$h(0)=0$.

Combining Eq. (A1) to Eq. (A2) leads to

$\frac{\partial h}{\partial t}=U-K v^{m}(L-x)^{m p}\left(\frac{\partial h}{\partial x}\right)^{n}$.

Let us note that, as drainage area tends towards zero at the divide, this equation is singular at $x=L$. This is commonly handled by defining a critical slope, $S_{\mathrm{c}}$, beyond which the stream power law is no more valid and colluvial and hillslope processes become dominant to maintain slope at $S=S_{\mathrm{c}}$ (Whipple and Tucker, 1999).

\section{A2 Steady-state solution to the uplift/stream power equation}

At steady state, we can write

$U=K v^{m}(L-x)^{m p}\left(\frac{\partial \bar{h}}{\partial x}\right)^{n}$

and the steady-state profile is

$$
\begin{aligned}
\bar{h}= & \left(\frac{U}{K v^{m}}\right)^{1 / n} \frac{1}{1-m p / n} \\
& {\left[L^{1-m p / n}-(L-x)^{1-m p / n}\right] . }
\end{aligned}
$$

The maximum height is

$$
H=\left(\frac{U}{K \nu^{m}}\right)^{1 / n} \frac{L^{1-m p / n}}{1-m p / n} .
$$

If we introduce dimensionless variables,

$x^{\prime}=x / L, h^{\prime}=h / H, t^{\prime}=t / \tau$

where $\tau=H / U$, Eq. (A4) becomes

$\frac{\partial h^{\prime}}{\partial t^{\prime}}=1-\left(1-x^{\prime}\right)^{m p}\left(\frac{\partial h^{\prime}}{\partial x^{\prime}}\right)^{n}$.

The boundary condition becomes

$h^{\prime}(0)=0$,

and the steady-state solution takes the dimensionless form:

$\overline{h^{\prime}}=1-\left(1-x^{\prime}\right)^{1-m p / n}$.

A similar expression can be found in Whipple and Tucker (1999).

\section{A3 Small perturbation in precipitation rate}

Let us consider how a small temporal perturbation in precipitation rate $\delta v(t)$ affects the steady-state solution. We assume that the solution scales linearly with the perturbation:

$h=\bar{h}+\delta h$

while still respecting the boundary condition:

$\delta h(0)=0$

Equation (A4) becomes

$\frac{\partial \delta h}{\partial t}=U-K(\bar{v}+\delta v)^{m}(L-x)^{m p}\left(\frac{\partial \bar{h}}{\partial x}+\frac{\partial \delta h}{\partial x}\right)^{n}$,

where $\bar{v}$ is the precipitation rate at steady state. Because both $\delta v$ and thus $\delta h$ are small, we can write

$$
\begin{aligned}
\frac{\partial \delta h}{\partial t} \approx & U-K\left(v^{m}+m v^{m-1} \delta v\right)(L-x)^{m p} \\
& {\left[\left(\frac{\partial \bar{h}}{\partial x}\right)^{n}+n\left(\frac{\partial \bar{h}}{\partial x}\right)^{n-1} \frac{\partial \delta h}{\partial x}\right] . }
\end{aligned}
$$

Using Eq. (A5) and keeping the terms $O(\delta v)$ and $O(\delta h)$ only, we obtain

$$
\frac{\partial \delta h}{\partial t} \approx-m \frac{\delta v}{\bar{v}} U-n K \bar{v}^{m}(L-x)^{m p}\left(\frac{\partial \bar{h}}{\partial x}\right)^{n-1} \frac{\partial \delta h}{\partial x} .
$$

Using Eq. (A5) again, we can write

$$
\begin{gathered}
\frac{\partial \delta h}{\partial t} \approx-m \frac{\delta v}{\bar{v}} U-n K^{1 / n} \bar{\nu}^{m / n} U^{(n-1) / n} \\
(L-x)^{m p / n} \frac{\partial \delta h}{\partial x}
\end{gathered}
$$


and by using Eq. (A7), we obtain

$\frac{\partial \delta h}{\partial t} \approx-m \frac{\delta v}{\bar{v}} U-\frac{n U}{H} \frac{L^{1-m p / n}}{1-m p / n}(L-x)^{m p / n} \frac{\partial \delta h}{\partial x}$.

Using again the dimensionless variables,

$\delta h^{\prime}=\delta h / H, \delta v^{\prime}=\delta v / \bar{v}, t^{\prime}=t / \tau, x^{\prime}=x / L$,

we obtain

$\frac{\partial \delta h^{\prime}}{\partial t^{\prime}} \approx-m \delta v^{\prime}-\frac{n}{1-m p / n}\left(1-x^{\prime}\right)^{m p / n} \frac{\partial \delta h^{\prime}}{\partial x^{\prime}}$.

If we integrate this equation over the length of the channel and introduce

$\hat{h^{\prime}}=\int_{0}^{1} \delta h^{\prime}\left(x^{\prime}\right) \mathrm{d} x^{\prime}$,

we obtain

$\frac{\partial \hat{h}^{\prime}}{\partial t^{\prime}} \approx-m \delta v^{\prime}-\frac{n}{1-m p / n} \int_{0}^{1}\left(1-x^{\prime}\right)^{m p / n} \frac{\partial \delta h^{\prime}}{\partial x^{\prime}} \mathrm{d} x^{\prime}$

and, by integrating by parts, we obtain

$\frac{\partial \hat{h}^{\prime}}{\partial t^{\prime}} \approx-m \delta v^{\prime}-\frac{m p}{1-m p / n} \int_{0}^{1}\left(1-x^{\prime}\right)^{m p / n-1} \delta h^{\prime} \mathrm{d} x^{\prime}$

as $\delta h^{\prime}(0)=0$.

Here we need to make a further assumption, which is unlikely to be valid in all situations, but it will allow us to derive an approximate solution which we will test numerically. Under the assumption that the ratio $m p / n$ is close to unity, we can neglect the term $\left(1-x^{\prime}\right)^{m p / n-1}$ under the integral sign. This leads to

$\frac{\partial \hat{h}^{\prime}}{\partial t^{\prime}} \approx-m \delta v^{\prime}-\frac{m p}{1-m p / n} \int_{0}^{1} \delta h^{\prime} \mathrm{d} x^{\prime}$

and

$\frac{\partial \hat{h}^{\prime}}{\partial t^{\prime}} \approx-m \delta v^{\prime}-\frac{m p}{1-m p / n} \hat{h^{\prime}}$.

\section{A4 Periodic perturbation in precipitation rate}

Assuming a periodic perturbation in precipitation rate which we express as

$\delta v^{\prime}=\delta v_{0}^{\prime} \sin \left(\alpha t^{\prime}\right)$,

we obtain the following solution:

$$
\begin{aligned}
\hat{h^{\prime}} & =\frac{m \delta v_{0}^{\prime}\left(\alpha \cos \left(\alpha t^{\prime}\right)-\frac{m p}{1-m p / n} \sin \left(\alpha t^{\prime}\right)\right)}{\alpha^{2}+\left(\frac{m p}{1-m p / n}\right)^{2}} \\
& +C_{0} e^{-\frac{m p}{1-m p / n} t^{\prime}} .
\end{aligned}
$$

The negative exponential term corresponds to the transient response of the system, which is not of interest to us here and we will neglect it from now on.

\section{A5 Predicted sedimentary flux}

The perturbation to the normalized sedimentary flux leaving the channel is given by

$$
\begin{aligned}
\delta Q^{\prime} & =\frac{\partial \hat{h}^{\prime}}{\partial t^{\prime}} \\
& =-\frac{\alpha m \delta v_{0}^{\prime}\left(\alpha \sin \left(\alpha t^{\prime}\right)+\frac{m p}{1-m p / n} \cos \left(\alpha t^{\prime}\right)\right)}{\alpha^{2}+\left(\frac{m p}{1-m p / n}\right)^{2}},
\end{aligned}
$$

which can also be expressed in the following form:

$\delta Q^{\prime} \approx \frac{\alpha m \delta v_{0}^{\prime}}{\sqrt{\alpha^{2}+\left(\frac{m p}{1-m p / n}\right)^{2}}} \sin \left(\alpha t^{\prime}+\theta^{\prime}\right)$,

where the lag, $\theta^{\prime}$, is given by

$\theta^{\prime}=\tan ^{-1}\left(\frac{1}{\alpha} \frac{m p}{1-m p / n}\right)$

and the amplification ratio, or gain, $G$, between normalized sedimentary flux variations and normalized precipitation variations, is given by

$G=\delta q^{\prime} / \delta v_{0}^{\prime}=\frac{\alpha m}{\sqrt{\alpha^{2}+\left(\frac{m p}{1-m p / n}\right)^{2}}}$.

Going back to the dimensional variables, we see that this solution corresponds to a signal that lags behind the forcing by a time:

$\theta=\frac{P}{2 \pi} \tan ^{-1}\left(\frac{P}{2 \pi \tau} \frac{m p}{1-m p / n}\right)$,

where $P$ is the period of forcing/climate change and $\tau$ is the characteristic time of the erosive system, i.e., the time it takes for erosion to come to equilibrium with tectonic uplift. 


\section{The Supplement related to this article is available online at doi:10.5194/-15-1-2015-supplement.}

Acknowledgements. We thank Sébastien Castelltort, Tom Coulthard and two anonymous reviewers for their very helpful comments on an earlier version of this manuscript.

Edited by: J. Willenbring

\section{References}

Anderson, R. S.: Modeling the tor-dotted crests, bedrock edges, and parabolic profiles of high alpine surfaces of the Wind River Range, Wyoming, Geomorphology, 46, 35-58, 2002.

Armitage, J. J., Duller, R. A., Whittaker, A. C., and Allen, P. A.: Transformation of tectonic and climatic signals from source to sedimentary archive, Nat. Geosci., 4, 1-5, 2011.

Boggart, P., van Balen, R., Kasse, C., and Vandenberghe, J.: Process-based modeling of fluvial system response to rapid climate change - I: model formulation and generic applications, Quaternary Sci. Rev., 22, 2077-2095, 2003.

Braconnot, P.: Modeling the last Glacial Maximum and miHolocene, Comptes Rendus Geoscience, 336, 711-719, 2004.

Braun, J. and Willett, S.: A very efficient $O(n)$, implicit and parallel method to solve the basic stream power law equation governing fluvial incision and landscape evolution, Geomorphology, 180181, 170-179, 2013.

Castelltort, S. and Van Den Driessche, J.: How plausible are highfrequency sediment supply-driven cycles in the stratigraphic record?, Sediment. Geol., 157, 3-13, 2003.

Champagnac, J.-D., Molnar, P., Sue, C., and Herman, F.: Tectonics, climate, and mountain topography, J. Geophys. Res., 117, B02403, doi:10.1029/2011JB008348, 2012.

Clemens, S. C., Prell, W., Murray, D., Shimmield, G., and Weedon, G.: Forcing mechanism of the Indian-ocean monsoon, Nature, 353, 720-725, 1991.

Clemens, S., Murray, D., and Prell, W.: Nonstationary phase of the plio-pleistocene Asian monsoon, Science, 274, 943-948, 1996.

De Boer, P. L. and Smith, D. G.: Orbital forcing and cyclic sequences, 19, 1-14, 1994.

Demenocal, P. and Rind, S.: Sensitivity of Asian and African climate to variations in seasonal insolation, glacial cover, seasurface temperature and Asian orography, J. Geophys. Res., 98, 7265-7287, 1993.

DiBiase, R. A. and Whipple, K. X.: The influence of erosion thresholds and runoff variability on the relationships among topography, climate, and erosion rate, J. Geophys. Res., 116, F04036, doi:10.1029/2011JF002095, 2011.

Dixon, J., Heimsath, A., Kaste, J., and Amundson, R.: Climatedriven processes of hillslope weathering, Geology, 37, 975-978, 2009.

Dosseto, A., Hesse, P., Maher, K., Fryirs, K., and Turner, S.: Climatic and vegetation control on sediment dynamics during the last glacial cycle, Geology, 38, 395-398, 2010.

Egholm, D., Nielsen, S., Pedersen, V., and Lesemann, J.-E.: Glacial effects limiting mountain height, Nature, 460, 884-887, 2009.
Godard, V., Tucker, G. E., Burch Fisher, G., Burbank, D. W., and Bookhagen, B.: Frequency-dependent landscape response to climatic forcing, Geophys. Res. Lett., 40, 859-863, doi:10.1002/grl.50253, 2013.

Gourlan, A., Meynadier, L., Allegre, C., Tapponier, P., Birck, J., and Joron, J.: Northern Hemisphere climate control of the Bengali rivers discharge during the past $4 \mathrm{Ma}$, Quaternary Sci. Rev., 29, 2482-2498, 2010.

Gourlan, A., Voisin, C., Chauvel, C., and Braun, J.: Delayed erosional response of the Hiamalayas to Milankovitch climate cycles, Geochem. Geophy. Geosy., submitted, 2014.

Hack, J. T.: Studies of longitudinal stream profiles in Virginia and Maryland, USGS Professional Paper 294, USGS, Washington, D.C., 97 pp., 1957.

Herman, F., Seward, D., Valla, P. G., Carter, A., Kohn, B., Willett, S. D., and Ehlers, T. A.: Worldwide acceleration of mountain erosion under a cooling climate, Nature, 504, 423-426, 2014.

Howard, A.: Equilibrium and time scales in geomorphology: application to sand-bed alluvial streams, Earth Surf. Proc. Land., 7, 303-325, 1982.

Howard, A.: A detachment-limited model of drainage basin evolution, Water Resour. Res., 30, 2261-2285, 1994.

Humphrey, N. F. and Heller, P. L.: Natural oscillations in coupled geomorphic systems: an alternative origin for cyclic sedimentation, Geology, 23, 499-502, 1995.

Hupp, C. R. and Osterkamp, W. R.: Riparian vegetation and fluvial geomorphic processes, Geomorphology, 14, 277-295, 1996.

Lague, D.: The stream power river incision model: evidence, theory and beyond, Earth Surf. Proc. Land., 39, 38-61, 2014.

Lague, D. and Hovius, N.: Discharge, discharge variability, and the bedrock channel profile, J. Geophys. Res., 110, F04006, doi:10.1029/2004JF000259, 2005.

Maher, K. and Chamberlain, C.: Hydrologic regulation of chemical weathering and the geologic Carbon cycle, Science, 343, 1502 1504, 2014.

Milankovitch, M.: Kanon der Erdbestrahlung und seine Andwendung auf das Eiszeiten-problem, Royal Serbian Academy, Belgrade, 1941.

Molnar, P. and England, P.: Late Cenozoic uplift of mountain ranges and global climate change: chicken and egg?, Nature, 346, 2934, 1990 .

Montgomery, D.: Valley incision and the uplift of mountain peaks, J. Geophys. Res., 99, 13913-13921, 1994.

Montgomery, D., Balco, G., and Willett, S.: Climate, tectonics, and the morphology of the Andes, Geology, 29, 579-582, 2001.

Paola, C., Heller, P. L., and Angevine, C. L.: The large-scale dynamics of grain-size variation in alluvial basins, 1: Theory, Basin Res., 4, 73-90, 1992.

Prell, W. and Kutzbach, J.: Monsoon variability over the past 150,000 years, J. Geophys. Res., 92, 8411-8425, 1987.

Rinaldo, A., Dietrich, W. E., Rigon, R., Vogel, G. K., and Rodrlguez-Lturbe, I.: Geomorphological signatures of varying climate, Nature, 374, 632-635, 1995.

Roe, G., Stolar, D., and Willett, S.: The sensitivity of a critical wedge orogen to climatic and tectonic forcing, in: Tectonics, Climate, and Landscape Evolution, edited by: Willett, S., Hovius, N., Brandon, M., and Fisher, D., GSA Special Publication 398, 227-239, 2005. 
Rossignolstrick, M.: African Monsoons, an immediate climate response to orbital insolation, Nature, 304, 46-49, 1983.

Simpson, G. and Castelltort, S.: Model shows that rivers transmit high-frequency climate cycles to the sedimentary record, Geology, 40, 1131-1134, 2012.

Strecker, M. R., Alonso, R. N., Bookhagen, B., Carrapa, B., Hilley, G. E., Sobel, E. R., and Trauth, M. H.: Tectonics and Climate of the Southern Central Andes, Annu. Rev. Earth Pl. Sc., 35, 747787, 2007.

Thomson, S., Brandon, M., Tomkin, J., Reiners, P. W., Vasquez, C., and Wilson, N.: Glaciation as a destructive and constructive control on mountain building, Nature, 467, 313-317, 2010.

Tucker, G. and Slingerland, R.: Drainage basin responses to climate change, Water Resour. Res., 33, 2031-2047, 1997.

Valla, P., Shuster, D., and van der Beek, P.: Significant increase in relief of the European Alps during mid-Pleistocene glaciations, Nat. Geosci., 4, 688-692, 2011.

Whipple, K. X.: The influence of climate on the tectonic evolution of mountain belts, Nat. Geosci., 2, 97-104, 2009.

Whipple, K. X. and Meade, B.: Orogen response to changes in climatic and tectonic forcing, Earth Planet. Sc. Lett., 243, 218-228, 2006.

Whipple, K. X. and Tucker, G.: Dynamics of the stream-power incision model: implications for height limits of mountain ranges, landscape response timescales and research needs, J. Geophys. Res., 104, 17661-17674, 1999.
Whipple, K. X., Kirby, E., and Brocklehurst, S.: Geomorphic limits to climate-induced increases in topographic relief, Nature, 401, 39-43, 1999.

Willett, S., Beaumont, C., and Fullsack, P.: Mechanical model for the tectonics of doubly-vergent compressional orogens, Geology, 21, 371-374, 1993.

Willett, S., Schlunegger, F., and Picotti, V.: Messinian climate change and erosional destruction of the central European Alps, Geology, 34, 613-616, 2006.

Willgoose, G.: A statistic for testing the elevation characteristics of landscape simulation models, J. Geophys. Res., 99, 1398713996, 1994.

Willgoose, G.: Mathematical Modeling of Whole Landscape Evolution, Annu. Rev. Earth Pl. Sc., 33, 443-459, 2005.

Wobus, C., Tucker, G., and Anderson, R.: Does climate change create distinctive patterns of landscape incision?, J. Geophys. Res., 115, F04008, doi:10.1029/2009JF001562, 2010.

Zhang, P., Molnar, P., and Downs, W.: Increased sedimentation rates and grain sizes 2-4 Myr ago due to the influence of climate change on erosion rates, Nature, 410, 891-897, 2001. 